\title{
HPV-16 Major Capsid Protein L1
}

National Cancer Institute

\section{Source}

National Cancer Institute. HPV-16 Major Capsid Protein L1. NCI Thesaurus. Code C17527.

HPV-16 major capsid protein L1 (505 aa, 56 kDa) is encoded by the human papillomavirus-16 L1 gene. This protein is involved in the formation of viral capsids. 